15. иенк эффективности огневого пор жения уд р ми р кет и огнем ртиллерии/ одред. . . обриков . - б.: « лея ринт», 2006. $-424 c$

16. уев . . рогнозиров ние в военном деле / . . уев, . . их йлов. - .. оенизд $m$, 1975. $-279 c$

17. неденко . . урс теории вероятностей / . . неденко. - .. $у к, 1988 .-448$ c.

18. ентиель . . еория вероятностей / . . ентиель. - .. ук , 1969.-576 с.

19. лимов . . льтерн тив методу м тем тической ст тистики / . . лимов. - .. н ние, 1980. -64 c.
20. утуб лин . . еория вероятностей/ . . утуб лин. - .. зд-во осковского универсиmem , 1972. $-230 \mathrm{c}$.

21. утуб лин . . p ницы применимости (вероятносно-ст тистические методы $и$ их возможности) / . . утутб лин. - .. н ние, 1977. $-63 c$

дійщл доред кцїі 5.10.2010 p.

ецензент: доктор технічних н ук, ст рший н уковий співробітник . . убков, к демія сухопутних військ, ьвів.

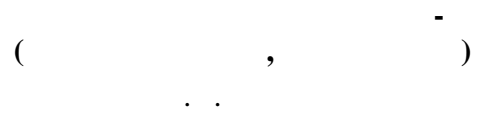

роведен н лиз существующих методов моделиров ния боевых действий н долгосрочную перспективу. ст новлено возможности их применения для д льнейшего решения проблемы формиров ния опер тивно-т ктических требов ний кперспективным систем м (комплекс м, обр зи, м) вооружения и военной техники.

лючевые слов : методы моделиров ния боевых действий, опер тивно-т ктические требов ния, вооружение и военн я техник.

\title{
ANALYSIS OF METHODS OF GROUNDING OPERATIONAL-TACTICAL REQUIREMENTS FOR PERSPECTIVE SYSTEMS (COMPLEXES, MODELS) ARMAMENT AND MILITARY MATERIEL
}

A.N. Kuprinenko

Analysis of existing methods of combat actions modeling for long-range perspective has been conducted. Possibilities of their employment for further solution of the problem of forming operational-tactical requirements for perspective systems (complexes, models) armament and military materiel have been established.

Keywords: methods of combat actions modeling, operational-tactical requirements, armament and military materiel.

\subsection{3:656.13}

. . уд рецкий ${ }^{1}$, . . р бч к ${ }^{1}, \ldots$ нинский ${ }^{2}, \ldots$ рокопенко $^{1}$

$1 \kappa$ демия сухопутных войск имени гетм н етр г йд чного, ьвов

или $л$ «

ст тье предложены н литический метод и метод имит ционного моделиров ния оптимиз ции $n$ р метров иифрового измерителя допплеровских ртиллерийских систем. ссмотрен структурн я схем иифровой системы ф зовой синхрониз иии, предст влены р зностные ур внения и перед точные функции, определены условия ее устойчивости. редст влен имит иионн я модель иифровой системы ф зовой синхрониз ции позволяющ я произвести оптимиз иию ее $n p$ метров, определить временные $x$ ктеристики и точность оценки $n$ р метров движения объектов для систем втономной н виг ции и б ллистической подготовки ртиллерийских систем.

лючевые слов : цифров я систем фзовой синхрониз ции, н литические и имит ицонные модели

\section{ведение}

ост новк проблемы. едение точного и своевременного ртиллерийского огня невозможно без к чественного проведения мероприятий топогеодезической, б ллистической, метеорологической подготовки, которые являются сост вными ч стями полной подготовки стрельбы. сновным

(c) . . уд рецкий, . . р бч к, . . нинский, . . рокопенко 
преимуществом полной подготовки для определения уст новок стрельбы есть то, что он обеспечив ет постоянную готовность ртиллерийских систем ( ) и подр зделений к стрельбе без пристрелки к к в н ступлении, т к и в обороне, нез висимо от погодных условий и в любое время суток [1]. сновным критерием т кой подготовки есть точность определения топогеодезической и 6 ллистической информ ции. оэтому в условиях современного боя возник ет кту льность доосн щения к ждой средств ми втом тического определения топогеодезической и б ллистической информ ции.

\section{н лиз последних}

публик ций. сновным средством получения информ ции о п р метр х движения в подсистем х втономной н виг ции и б ллистической подготовки являются допплеровские

непрерывным излучением. риемоперед ющие модули т ких формируют сигн лы допплеровских ч стот, которые в д льнейшем обр б тыв ются измерителем н основе цифровой системы фзовой синхрониз ции ( ), конструктивно совмещенным с втом тизиров нным формиров телем уст новок стрельбы ( ) [2].

н стоящее время теория непрерывных систем ф зовой синхрониз ции дост точно р звит и изложен во многих фунд мент льных публик циях [3, 4], в то же время теория пережив ет период бурного р звития и д же уд чные попытки систем тизиров ть отдельные публик ции $[5,6]$ не д ют декв тного решения всех многочисленных проблем ре лиз ции т ких систем.

елью ст тьи является р зр ботк н литических соотношений и прогр мм имит ционного моделиров ния $\mathrm{H}$ для оптимиз ции п р метров цифрового измерителя допплеровских , предн зн ченных для оценки $\mathrm{x}$ р ктеристик движения в подсистем х втономной н виг ции и б ллистической подготовки ртиллерийских систем.

\section{сновН Я ч сть}

елесообр зность проведенного в [2] выбор цифровой ре лиз ции измерителя для обеспечения

н виг ционной и $б$ ллистической информ цией обосновыв ется тем, что цифровые методы обр ботки сигн лов позволяют зн чительно увеличить ст бильность п р метров пп р туры и дин мический ди п зон р боты, обеспечить иде льные з помин ние и н копление сигн лов, удобство измерения п р метров и сопряжение с цифровой вычислительной м шиной. систем х синхрониз ции и измерения п р метров отр женных сигн лов цифровые методы, в ч стности, позволяют существенно уменьшить эквив лентную полосу следящей системы при одновременном р сширении полосы синхронизм, осуществить норм льную р боту при очень низком отношении сигн л - шум во входной полосе. роме того, они позволяют решить ряд других 3 д ч, вызыв ющих большие, иногд пр ктически непреодолимые трудности при использов нии н логовой техники [5]. труктурн я схем р ссмотренного в [2] цифрового измерителя н основе приведен н рис. 1.

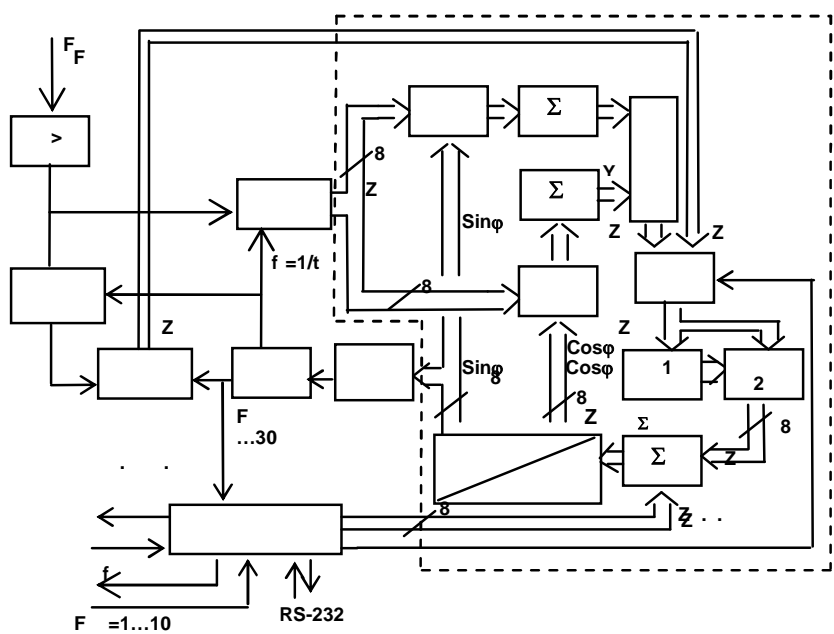

uc.1. труктурн я схем , где:

- импульсный ч стотно-ф зовый дискримин тор, - дискримин тор, - комп р тор, - коммут тор кодов, - н копительный сумм тор, - функцион льный преобр зов тель, - формиров тель импульсов,

- прогр ммируем я логическ я интегр льн я схем

сновной особенностью предст вленного н рис. 1 измерителя является дискретиз ции по времени и кв нтов ние по уровню обр $б$ тыв емых сигн лов, что созд ет ряд специфических особенностей при его проектиров нии - усложняет лгоритмы достижения 3 д нных точностных х р ктеристик и огр ничив ет обл сть устойчивости.

н литический метод выбор п р метров цифровых измерителей с проводится $\mathrm{H}$ основе н лиз их перед точных функций, что, в отличии от н логовой ре лиз ции, требует переход от дифференци льных ур внений $\mathrm{K}$ p зностным с использов нием Z-преобр зов ния. зностное ур внение со вторым порядком ст тизм имеет вид [7]

$$
\begin{aligned}
& \varphi_{[R]}+\left(K_{b 1} / 2+K_{b 2} / 2-2\right) \cdot \varphi_{[R-1]}+\left(K_{b 2} / 2+1\right) \times \\
& \times \varphi_{[R-2]}-K_{b 1} / 2 \cdot \varphi_{[R-3]}=\varphi_{C[R]}-2 \varphi_{C[R-1]}+ \\
& +\varphi_{C[R-2]}-\left(K_{b 1}+K_{b 2}\right) \varphi\left[{ }_{[R-1}+K_{b 1} \varphi[R-2],\right.
\end{aligned}
$$


где $\quad K_{b 1}=2 k_{g} K_{1} \pi \Delta F T_{H}, \quad K_{b 2}=2 k_{g} K_{2} \pi \Delta F T_{H}$

безр змерные коэффициенты перед чи соответственно по пропорцион льной и интегрирующей ветвям петлевого фильтр , $\varphi_{C}-$ ф з сигн л н входе, $k_{g}$ - коэффициент перед чи дискримин тор , $K_{1}, K_{2}$ - коэффициенты перед чи цифрового фильтр соответственно по пропорцион льным и интегрирующим петлям, $\Delta F$ - дискрет перестройки цифрового синтез тор ч стоты, $T$ - время предв рительного усреднения отсчетов в н копительном сумм торе перед их функцион льной обр боткой $\quad-\quad$ ре лиз цией лгоритмов дискримин тор и петлевого фильтр , $R-$ номер т кт регулиров ния.

свою очередь, интерв л предв рительного усреднения цифровых отсчетов $T$ связ н ч стотой $f$ (периодом $t$ ) дискретиз ции через емкость н копительного сумм тор со сбросом C выр жением

$$
=t \quad=\frac{}{f} .
$$

еред точные х р ктеризующие функции флюкту ционные х р ктеристики, описыв ются выр жениями:

$$
\begin{aligned}
& K_{g}(z)=\left(z^{3}-2 z^{2}+z\right) /\left[z^{3}+\left(K_{b 1} / 2+K_{b 2} / 2-2\right) \times\right. \\
& \left.\times z^{2}+\left(K_{b 2} / 2+1\right) \cdot z-K_{b 1} / 2\right] ; \\
& \quad K \quad(z)=\left[-\left(K_{b 1}+K_{b 2}\right) z^{2}+K_{b 1} \cdot z\right] /\left[z^{3}+\right. \\
& \quad+\left(K_{b 1} / 2+K_{b 2} / 2-2\right) \cdot z^{2}+\left(K_{b 2} / 2+1\right) \times \\
& \left.\quad \times z-K_{b 1} / 2\right],
\end{aligned}
$$

где $Z$ - преобр зов ние, $K_{u}, K_{g}$ - перед точные функции $\quad$, х р ктеризующие ее дин мические и флюкту ционные свойств .

ри этом дин мическ я ошибк $М \varphi$

при входном воздействии

$$
\Omega_{C}(t)=\alpha t, \varphi_{C}(t)=\alpha t^{2} / 2
$$

имеет вид

$$
M \varphi=\alpha T^{2} / K_{b 2},
$$

где $\alpha-$ скорость изменения допплеровской ч стоты.

люкту ционн я ошибк описыв ется выр жением

$$
\begin{aligned}
& \sigma_{\varphi}^{2}=N_{e}^{*}\left[K_{b 1}^{2}\left(K_{b 1}+2\right)+K_{b 2}\left(K_{b 1}^{2}+K_{b 1} K_{b 2} / 4+\right.\right. \\
& \left.\left.+K_{b 1}+K_{b 2} / 2+2\right)\right] /\left[2 K_{b 1}\left(2-K_{b 1}\right)-\right. \\
& \left.-K_{b 2}\left(2+K_{b 1}\right)\right] T_{H} .
\end{aligned}
$$

р ктеристический многочлен выр жения (7)

$$
\begin{aligned}
P(z)=z^{3}+( & \left.K_{b 1} / 2+K_{b 2} / 2-2\right) \cdot z^{2}+ \\
& +\left(K_{b 2} / 2+1\right) \cdot z-K_{b 1} / 2
\end{aligned}
$$

д ет следующие условия устойчивости

$$
\left\{\begin{array}{l}
K_{b 1}>0, \\
K_{b 2}>0, \\
K_{b 2}+2 K_{b 1}-4<0, \\
2 K_{b 1} K_{b 2}+4 K_{b 2}-8 K_{b 1}+4 K_{b 1}^{2}<0 .
\end{array}\right.
$$

риведенные выр жения позволяют получить ориентировочные п р метры и не учитыв ют погрешностей предшествующего н логового тр кт, огр ниченности р зрядной сетки вычислителя при ре лиз ции лгоритмов дискримин торов и ряд других особенностей цифровой ре лиз ции, т ких, н пример, к к некр тность интерв л усреднения в цифровых интегр тор х $T$ периоду опорной ч стоты и др.

оэтому для оптимиз ции сост в цифрового измерителя, выбор интерв л усреднения кв др турных отсчетов цифровых сигн лов $T$

(интерв л «вторичной» дискретиз ции), лгоритмов дискримин тор , структуры и коэффициентов петлевого фильтр р зр бот ны лгоритмы и прогр ммы ст тистического синтез, позволяющие оценить результ ты н литического метод путем имит ционного моделиров ния $\mathrm{H}$

[7]. ни позволяют при р зных отношениях сигн л/шум н входе системы синхрониз ции провести н лиз р боты к к отдельных ее сост вных ч стей, т к и з мкнутой в целом, уточнить числовые зн чения п р метров, полученных в результ те н литического синтез, определить точность оценки п р метров движения объектов цифровым измерителем, д ть пр ктические рекоменд ции для его ре лиз ции н современной элементной 6 зе. труктурн я схем модели предст влен н рис. 2.

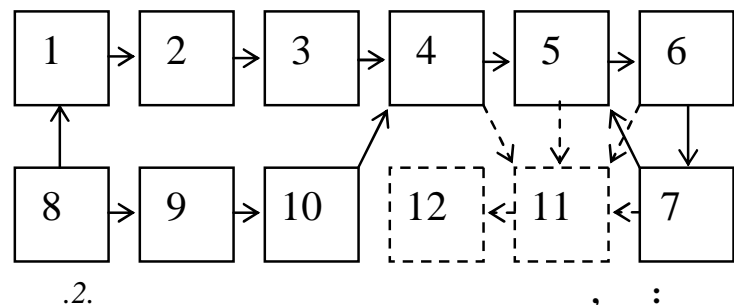

1 - модель входных сигн лов, 2 - модель входных цепей,

3 - , 4 - сумм тор, 5 - модель дискримин торов,

6 - модель петлевых фильтров, 7 - модель синтез тор ,

8 - модель движения цели, 9 - модель формиров теля отношения сигн л/шум, 10 - модель генер тор шум , 11 - модель ст тистической обр ботки, оценки точности следящего измерителя, 12 - модель упр вляемой системы генер ции гр фиков 
унктирными линиями пок з ны блоки и связи модели, которые обеспечив ют ст тистическую обр ботку и отобр жение полученных результ тов моделиров ния.

зр бот нные в [7] прогр ммы предст вляют собой м тем тическую модель, лгоритмы р боты которой $з$ д ются с помощью ук з телей модуля н ч льных условий прогр ммы и д лее в процессе моделиров ния не меняются. основу р боты модели положен «цикл измерения» $T$ - промежуток времени, 3 который формируется интерв л н копления кв др турных сост вляющих входного допплеровского сигн л .

о сути дел, н протяжении этого цикл формируется интерв л «вторичной» дискретиз ции.

д льнейшем интерв л х формируются лгоритмы дискримин торов и петлевого фильтр и определяется 3 держк сигн л упр вления цифровым синтез тором опорной ч стоты $Z_{\varphi_{\text {выx } \Sigma}}$ и кв др турных сост вляющих опорного сигн л относительно кв др турных сост вляющих входного сигн л .

роме функцион льных элементов цифрового измерителя ( н лого-цифрового кв др турного преобр зов теля ( ), н копительных сумм торов, формирующих интерв л $T$ синтез тор опорной ч стоты, дискримин торов и петлевого фильтр ) прогр ммно ре лизов ны м тем тические модели следующих устройств:

- генер тор входного сигн л ;

- входных цепей, которые функцион льно и конструктивно предшествуют и формируют мплитудно-ч стотную х р ктеристику н логового тр кт ;

- упр вляемой системы генер ции гр фиков, котор я позволяет визу льно отобр ж ть результ ты моделиров ния;

- блок ст тистической обр ботки результ тов и оценки х р ктеристик точности измерителя.

ссмотрим особенности ре лиз ции к ждой их этих сост вных ч стей.

енер тор входного сигн л формирует выборку входного сигн л допплеровской ч стоты, в совокупности с эт лонным г уссовским шумом.

одель входного сигн л 1 в 3 висимости от 3 д нной в 8 модели движения цели формирует в 3 д нный момент времени зн чение допплеровского смещения ч стоты. одель входных цепей 2 н кл дыв ет н сформиров нный в 1 сигн л огр ничения, которые определяются мплитудноч стотной х р ктеристикой предшествующего н логового тр кт . ормиров тель входного отношения сигн л/шум 9 формирует зн чение этого отношения в 3 д нный момент времени в 3 висимости от 3 д нной в 8 модели движения цели. олученное зн чение отношения сигн л/шум является условием 3 пуск генер тор шум 10 (генер тор случ йных чисел). олученные в генер торе шум 10 числовые зн чения шум скл дыв ются в сумм торе 4 с кв др турными отсчет ми допплеровского сигн л с выход

3 и усредненные н интерв ле $T$ поступ ют н дискримин тор 5, н второй вход которого поступ ет сигн л с выход синтез тор 7. формиров нный н выходе дискримин тор 5 сигн л р ссогл сов ния входного и опорного сигн лов усредняется петлевым фильтром 6 и поступ ет н упр вляющий вход синтез тор 7.

одели сост вных ч стей измерителя (дискримин тор , петлевого фильтр , синтез тор ) предст вляют собой модули, функционирующие в полном соответствии с их физической ре лиз цией в оэтому в модели эти модули р бот ют к к модули с фиксиров нной 3 пятой, имеющие огр ниченную р зрядность. гр ничение p зрядности в $p$ зр бот нной модели предст влено к к дополнительный шум, вносимый в конкретную точку вычислительного процесс . оскольку в процессе моделиров ния генерируется зн чительный объем информ ции, упр вляем я систем генер ции гр фиков 12 позволяет упр влять процессом сбор и визу лиз ции информ ции о р боте модели.

истем сбор и ст тистической обр ботки результ тов 11 предст вляет собой м тем тический пп р т, который позволяет оценить результ ты моделиров ния числовыми величин ми м тем тическим ожид нием, отклонением, дисперсией. роме того, н нее возложены функции формиров ния гр фиков конечных $з$ висимостей. пример, з висимости величины отклик н выходе ч стотного дискримин тор от уровня сигн л н входе.

\section{Ы В ОД Ы}

ерспективным н пр влением в определении п р метров движения в систем $\mathrm{x}$ втономной н виг ции и б ллистической подготовки ртиллерийских систем являются цифровые измерители допплеровских н основе цифровой системы ф зовой синхрониз ции. роведенные исследов ния цифровых измерителей пок з ли, что н сегодняшний день н литические методы (выр жения 1-8) позволяют определить лишь ориентировочные зн чения п р метров цифрового измерителя.

то же время методы имит ционного моделиров ния позволяют произвести н лиз 
p боты к к отдельных сост вных ч стей, т к и 3 мкнутой в целом, уточнить их п р метры, полученные в результ те н литического синтез, определить временные х р ктеристики и точность оценки п р метров движения в систем $\mathrm{x}$ втономной н виг ции и б ллистической подготовки ртиллерийских систем.

\section{писок литер туры}

1. трельб и упр вление огнем н земной ртиллерии. - оенное изд тельство инистерств бороны . - оскв, 1976.

2. уд рецкий . . собенности построения иифровых измерителей допплеровских для обеспечения ртиллерийских систем н виг ционной $u$ б ллистической информ иией / . . уд рецкий, . . ртиненко, . . p н// тері ли IV міжн родної н уково-технічної конференції -2009. стин 2. іниия, 2009. -96 c.

3. тиффлер ж. ж. еория синхронной связи. ер. с нгл./ одред. . . бидулин . - .. вязь, 1975.

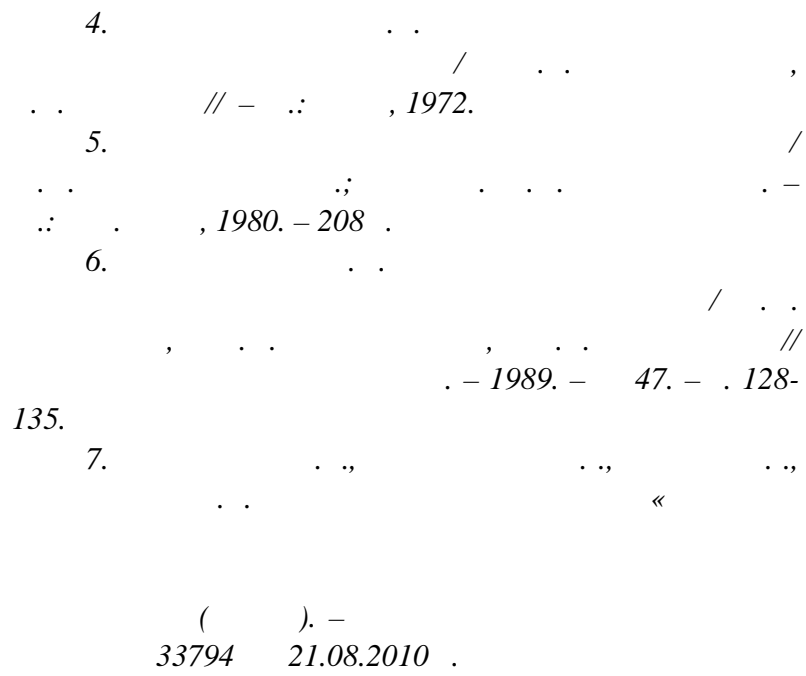

5. ифровые системы ф зовой синхрониз ции / одзишский и др.; од ред. . . о одзишского. $\therefore \quad$ ов.р дио, 1980. -208 c.

6. уд рецкий . . н лиз микропроцессорных систем синхрониз иии в импульсном приближении / . . уд рецкий, . . одзишский, . . ымрин // еоретическ я электротехник . - 1989. - № 47. - с. 128135.

7. нінський . ., уд рецький .,, р бчк .., рокопенко . . омпьютерн прогр $м$ «рогр $м$ визн чення $m$ оптиміз ції $n$ р метрів цифрового вимірюв ч н основі цифрових систем фзової синхроніз ції ( ). - відоцтво про реєст цію пр в н твір № 33794 від 21.08.2010 p.

оступил в ред кцию 9.11.2010 2.

ецензент: доктор технических н ук, ст рший н учный сотрудник . . убков, к демия сухопутных войск имени гетм н етр г йд чного, ьвов.

. . уд рецький, . . р бч к, . . н нінський, . . рокопенко

ст тті розглянуті н літичний метод і метод іміт ційного моделюв ння оптиміз ції $n$ р метрів цифрового вимірюв ч допплеровських ртилерійських систем. озглянут структурн схем иифрової системи ф зової синхроніз ції, предст влені різницеві рівняння і перед точні функції, визн чені умови їі стійкості. редст влен іміт ційн модель цифрової системи ф зової синхроніз ції, як дозволяе провести оптиміз цію їі $n p$ метрів, визн чети ч сові $x$ р ктеристики і точність оцінки $n$ р метрів руху об'єктів для систем втономної н віг ції $m$ б лістичної підготовки ртилерійських систем.

лючьові слов : цифров систем ф зової синхроніз ції, н літичні $m$ іміт ційні моделі

\section{METHODS OF OPTIMIZATION OF THE DIGITAL INSTRUMENT PARAMETERS OF THE ARTILLERY SYSTEMS DOPPLER RADARS}

\section{Y. I. Budaretskyi, V.I. Hrabchak, V.A. Kaninskyi, V.V. Prokopenko}

The article presents the analytical methods and the method of the imitation modeling of the parameters of the Doppler radar of the artillery system optimization. The structural scheme of the digital system of the phase synchronizing is viewed; differential equations and transmission functions are presented and the terms of their stability are defined. Presented imitation digital model of the phase synchronization allows to perform the optimization of its parameters, defines its temporary characteristics and the accuracy estimation of the parameters of objects' movement for the system of autonomic navigation and ballistic preparation of the artillery system.

Key words: digital system of the phase synchronization, analytical and imitation models. 